SESSION 2109

\title{
INTERPRETATION OF ENGINEERING AND NON-ENGINEERING SKILLS DURING TRANSITION FROM BEING A FRESHMAN TO A GRADUATING ENGINEER
}

\author{
Devdas Shetty* and Susan Coleman** \\ University of Hartford, West Hartford \\ CT 06117, Tel : (860) 768 - 4615 \\ * College of Engineering $\quad * *$ Barney School of Business
}

\begin{abstract}
This paper provides an overview of the results of student skill assessment as students gradually progress from freshman to senior year. The curriculum chosen was a revised engineering curriculum involving all the four years of the program. The curriculum change was necessitated by the implementation of a NSF- Action Agenda Grant, "Integrating Engineering Design with Humanities, Social Sciences, Sciences and Mathematics". The major curriculum change involved the following courses and instructional blocks. At the freshman year, the students were introduced to integrated learning blocks; at the sophomore year, the students were exposed to a new course on Engineering by Design with ethical component; at the junior year, the students are exposed to engineering practice; and at the senior year, the students undertake capstone projects from the industry. The assessment was done using a set of questionnaires that considered the groups of "Skill Clusters": Engineering Skills, Computer Skills, Communication Skills, and Management Skills. The students were exposed to different skill levels depending on their progression into the engineering curriculum. The results provided some insight into the student's systematic self-assessment of skill levels, as he / she progresses from first year to the final year. Based on the results, a feedback and continuous improvement mechanism is being developed.
\end{abstract}

Background

Curriculum Restructuring - Freshman Level:

In the last decade, there have been nationwide efforts in restructuring freshman curricula. Accordingly, the University of Hartford had redesigned the freshman program in engineering. This has helped the students to be exposed to fundamental engineering concepts in their freshman year side by side with science and humanities courses. Although the assessment of this first year program showed positive impact on student performance, the fragmented structure of the first -year curriculum still created problems in terms of student learning. Students seldom relate engineering topics to math, science, social science or writing.

"Proceedings of the 2002 American Society for Engineering Education Annual Conference \& Exposition Copyright (C) 2002, American Society for Engineering Education" 
Curriculum Restructuring - Establishing Linkages:

The problem of fragmented structure was overcome with the creation of unique course combinations where faculty from engineering, math, science, humanities, and social science worked together to define student learning outcomes for project-based curricula. Engineering and non-engineering courses were clustered into integrated First-Year Interest Groups (FIGs). Engineering and interdisciplinary courses were paired in the sophomore and junior year, by emphasizing collaborative projects involving engineering and non-engineering students. The integrated learning blocks created for four years of curriculum are shown in Figure 1.

Curriculum Restructuring - Design Integration:

The integration of applied research and contextualized design throughout the engineering curriculum, started from a design-based, freshman-level course and progressing through intermediate courses at the sophomore and junior level, culminating in the capstone design experience at the senior level. The introduction of design-oriented courses in each year of the engineering curriculum has given the students an opportunity to make connections between various courses and obtain a better perspective of engineering practice. For each of the four years, design-oriented courses have been established, as shown in Figure 2. Both technical and non-technical aspects of design are treated in depth using lectures, case studies and collaborative group projects. These courses and design projects provide the skills in problem solving, communication, computer skills, ethics, time management, team building skills, and business knowledge in addition to technical knowledge.

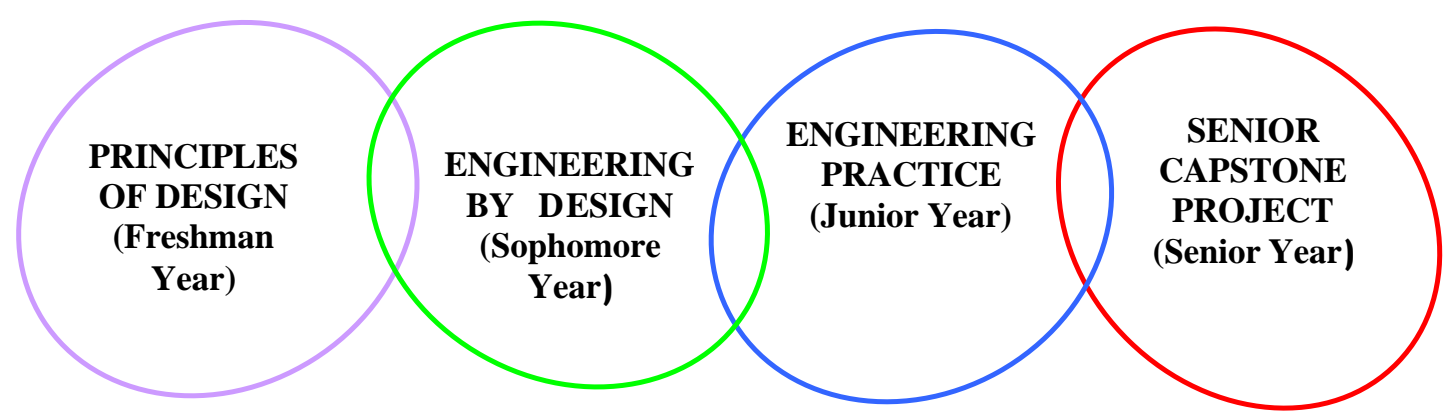

Figure 2: Design Oriented Courses through out The Engineering Curriculum 


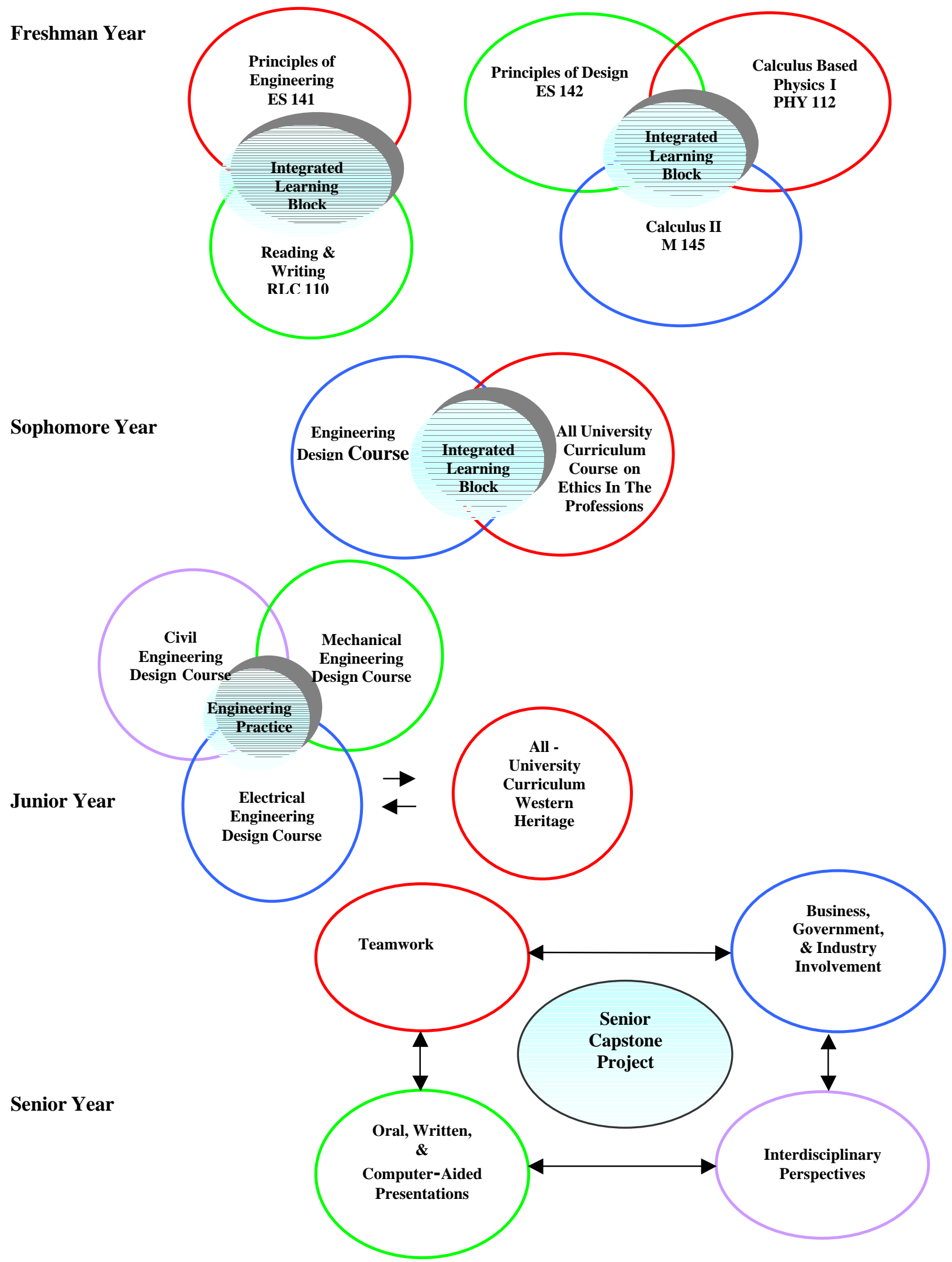

Figure 1: Elements of the redesigned curriculum

"Proceedings of the 2002 American Society for Engineering Education Annual Conference \& Exposition Copyright (C) 2002, American Society for Engineering Education" 


\section{Assessment of curricular reforms}

In order to assess the impact of these curricular reforms, we had created a questionnaire for each course and asked the students to give their feedback on a five-point scale. The questionnaires are shown in the appendix.

These questions were based on the course outcomes. The questions are grouped based on the skill clusters, for better interpretation. The skill clusters chosen were,

1. Engineering Skills

2. Computer Skills

3. Communication skills

4. Management skills

5. Connection to other courses

6. Resource utilization skills

The last two groups of questions were not considered for this paper. The ratings given by students for the selected skill clusters are shown in Table 1.

Engineering Skills: The basic knowledge of sciences and engineering provide the students the skills for problem solving. The learning outcomes include challenging the way things are done, generating many potential solutions and demonstrating openness to new ideas. The assessment rubric includes demonstrating awareness of how various engineering disciplines complement each other, understanding the design process from concept to prototyping, problem definition, analyzing problems from different viewpoints, and anticipating problems and developing contingency plans. Throughout their college career, students are encouraged to develop a strong work ethic, and to be self-motivated to achieve excellence in the field in which they work. The assessment attributes include a measure of their professionalism, their response to suggestions or criticism, and their use of ethical component in their decision-making strategy and consideration of the implication of the project for the community.

Computer Skills: It is important that the engineering graduates become computer literates. The assessment of computer skills is normally done by rating the quality of presentation in view of the engineering software used. The other important factors are use of graphics and simulation tool, and the extent of on-line research.

Communication Skills: $\quad$ Students gain the ability to effectively communicate technical and on-technical issues through both verbal and written skills sufficient to permit them to apply those skills in professional practice. Special attention needs to be paid to understanding the varying needs of technical and non-technical readers, organizing written materials in a logical sequence to enhance readers' comprehension and effectively applying presentation tools such as multimedia applications. The assessment tool rates the quality of individual and team presentation, use of presentation software, supplementary presentation materials, and written skills.

Management Skills: Students gain knowledge of basic project management/business skills sufficient to permit them to apply those skills in practice to the management of engineering

"Proceedings of the 2002 American Society for Engineering Education Annual Conference \& Exposition Copyright (C) 2002, American Society for Engineering Education" 
projects. Clarifying task requirements, creating an action plan, prioritizing milestones and taking corrective actions are important aspects of this area of competence. Modern business management techniques and tools are used to judge if the project is attuned to the needs of the client; whether solutions meet the desired needs; the effectiveness of decision making, and the effectiveness of cost analysis and time management. Students effectively manage the team as a group and help reconcile differences of opinion among team members. The student outcomes include demonstrating ability to take a leadership role in support of team goals. Indicators are used to provide evidence of desired performance such as group dynamics, even distribution of the workload, and evaluation of effective performance of assigned roles.

Interpretation of results

Based on data obtained from Table 1, the values were plotted to find the trend in the rankings over the four-year of curriculum. The graph is shown in Figure 3.

\begin{tabular}{|c|c|c|c|c|}
\hline SKILL CLUSTER TYPE & ES 141 & ES 142 & ES242 & CE 460 \\
\hline ENGINEERING SKILLS & 4.08 & 3.95 & 4.09 & 4.37 \\
\hline COMMUNICATION SKILLS & 4.12 & 4.52 & 3.57 & 4.1 \\
\hline COMPUTER SKILLS & 4.32 & 4.68 & 3.74 & 4.15 \\
\hline MANAGEMENT SKILLS & 4.03 & 3.91 & 3.78 & 3.6 \\
\hline
\end{tabular}

ES141 - Principles of Engineering ES142 - Principles of Design

ES242 - Engineering by Design $\quad$ CE460 - Civil Engg. Senior capstone Project

Table 1: Rating of Skill Clusters

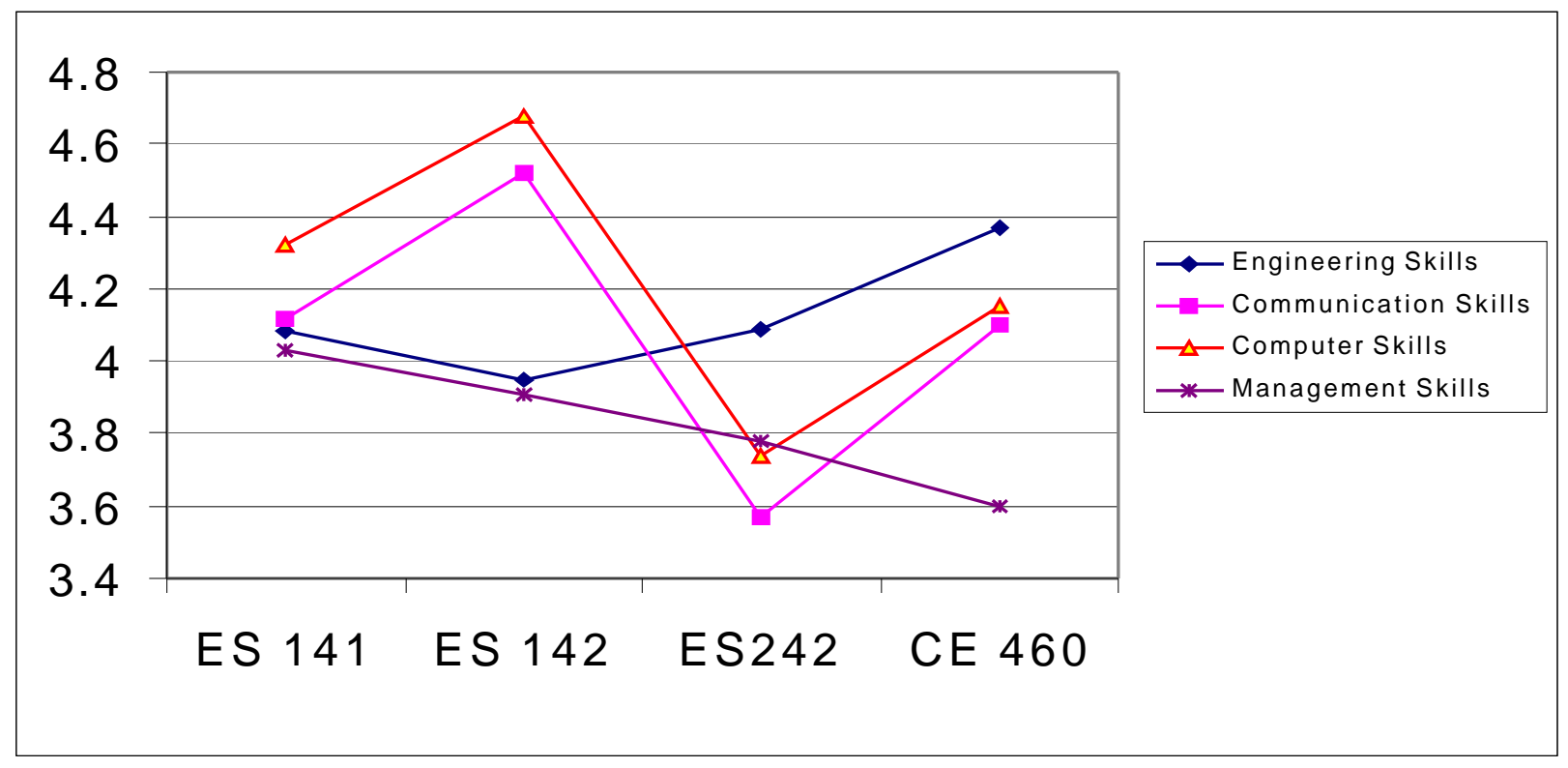

Figure 3: Ranking Trend of Skill Clusters

"Proceedings of the 2002 American Society for Engineering Education Annual Conference \& Exposition Copyright (C) 2002, American Society for Engineering Education" 
The results of table1 and figure 3 provide changing perceptionlon of the students regarding the identified skills as they progress from the freshman year to the senior year. From the skillranking trend, we can see the students' different phases of skill acquisition and the gradual realization, on the part of students, that their skills were not at a level they might previously have believed.

\section{Student Learning Phases:}

The skills can broadly be classified into three phases (shown in Figure 4)

1. Personal phase - computer skills, engineering skills;

2. Interpersonal phase - communication skills;

3. Leadership phase - management skills.

At the initial phase, all students try to learn their personal skills. As the student moves into the second phase, the student begins to doubt about his/her abilities in the personal skills. By the time the student is sufficiently skilled in the second phase, he/she regains confidence over the personal skills. Thus each successive step in the skills hierarchy forces students to re-examine their mastery of lower level skills and reinforces learning, since students cannot satisfy the higher level skill requirements without first gaining competence in the lower level skills.
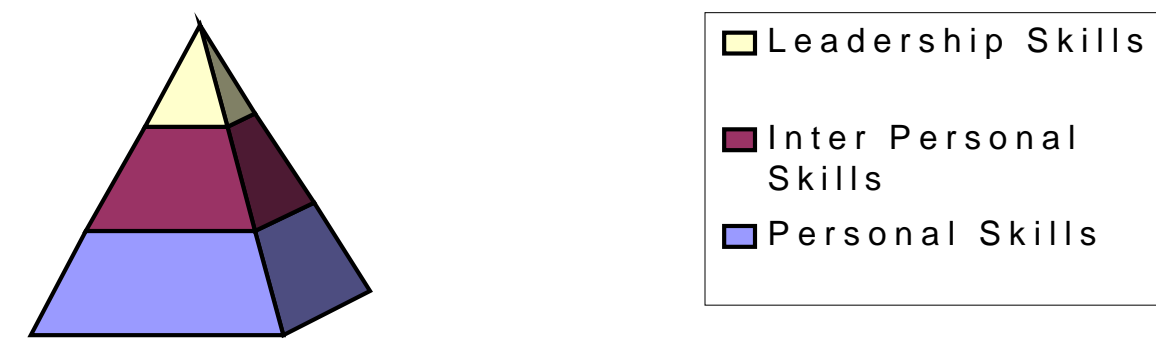

\section{Figure 4: Students Learning Phases}

\section{Freshman Year Students Skills Rating:}

From Figures 5 and 6, we can see that, as expected, the freshman students ranked their skills in the following order

1. Computer skills,

2. Communication skills,

3. Engineering skills, and

4. Management skills. 


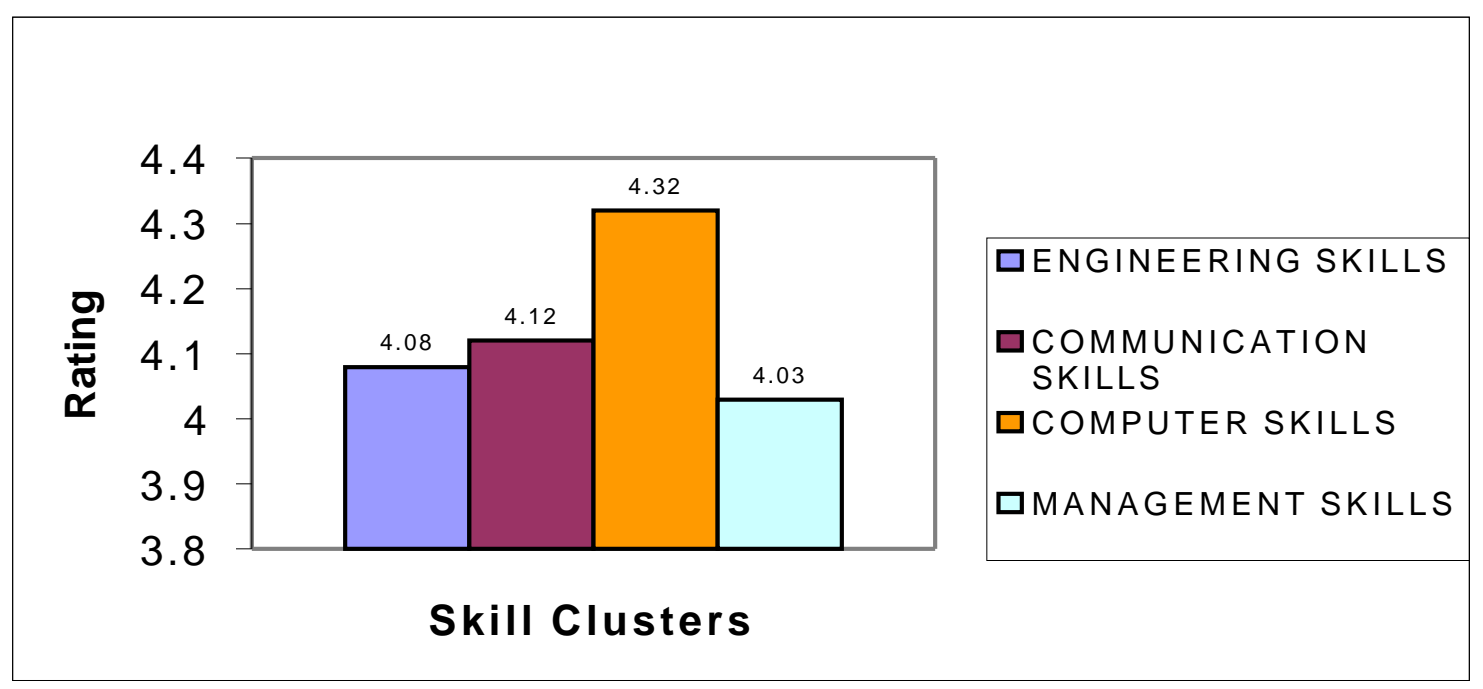

Figure 5: Skill rating by students of 'Principles of Engineering'

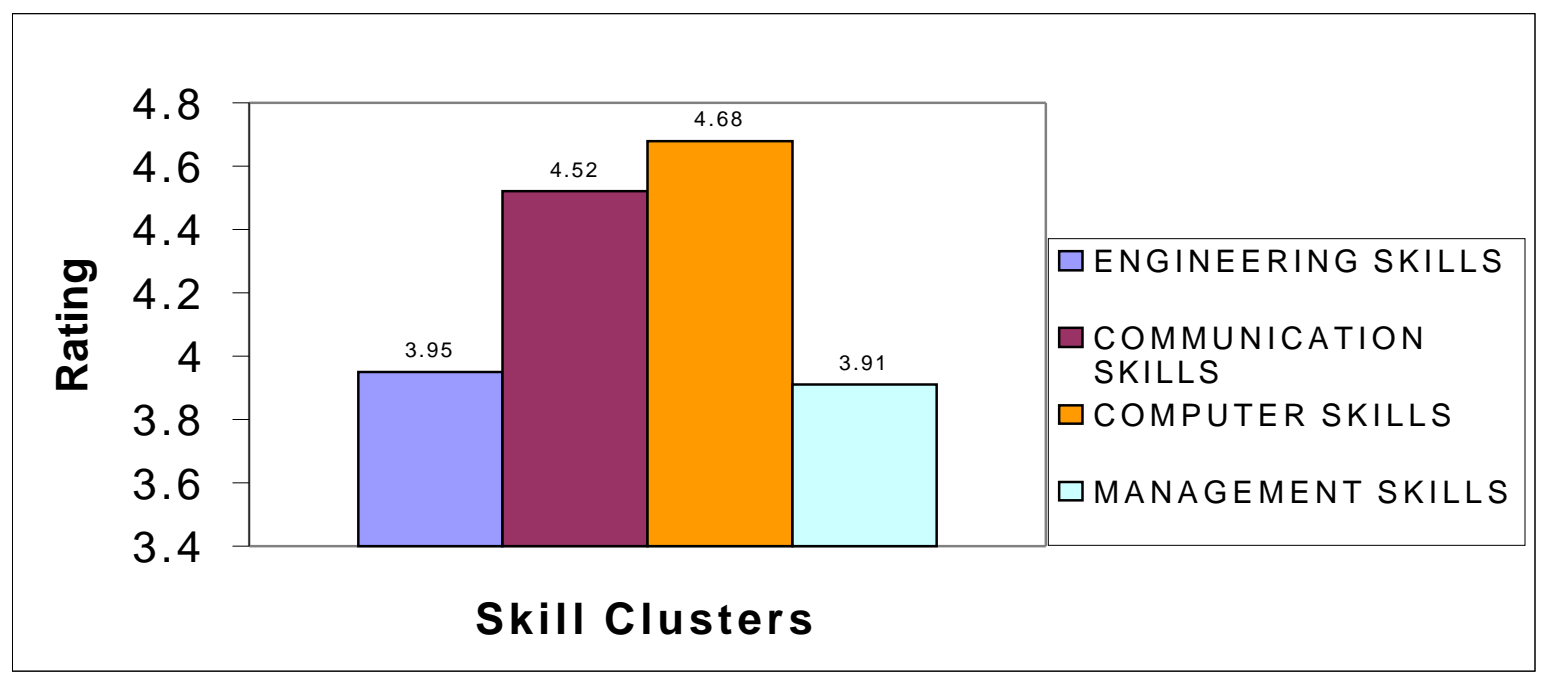

\section{Figure 6: Skill rating by students of 'Principles of Design'}

During the freshman year, they are taught graphic communication; reading and writing; and computer programming. They tend to rate their computer skills as being relatively high. Since these students are in their personal phase and have not yet entered the interpersonal phase, they give their communication skills a lower rating.

Also, since freshmen have only a brief introduction of the engineering principles, they are yet to realize the actual potential of Engineering Skills. Finally, freshmen, who are in the personal phase, have little understanding for the management skills, which fall under the leadership phase.

\section{Sophomore Year Students Skill Rating:}

The ratings given by the sophomore students are plotted in Figure 7. During the sophomore year, the ranking is as follows 
1. Engineering skills,

2. Management skills,

3. Computer skills, and

4. Communication skills

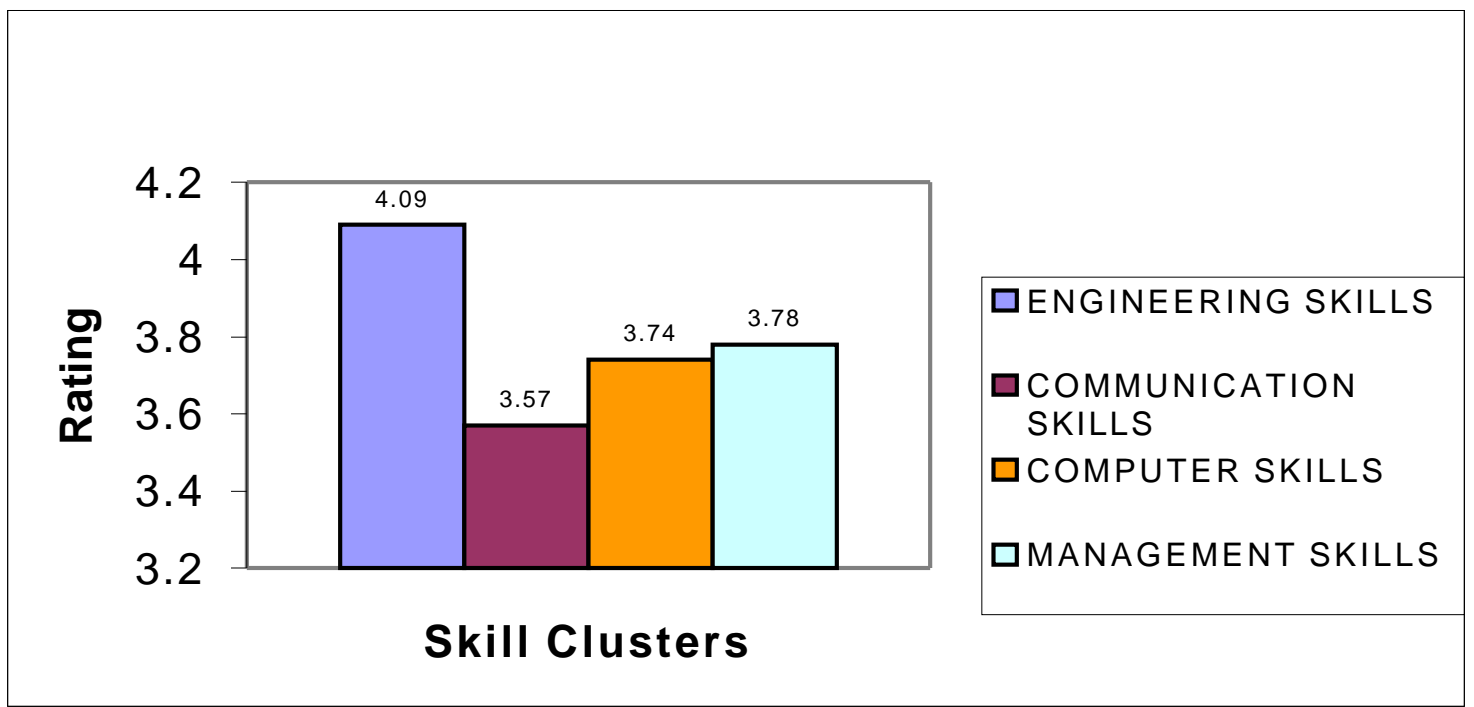

\section{Figure 7: Skill rating by students of 'Engineering by Design'}

The sophomore years focuses heavily on engineering courses, so students tend to give more importance to their engineering skills. Also they tend to set high standards for their management skills, since they are now in the interpersonal phase. As they venture into learning the interpersonal skills, they become aware that their previously acquired computer skills are not sufficient. Since they have to make a lot of presentations and are moving toward the leadership phase, students also begin to feel that their communication skills are less than adequate.

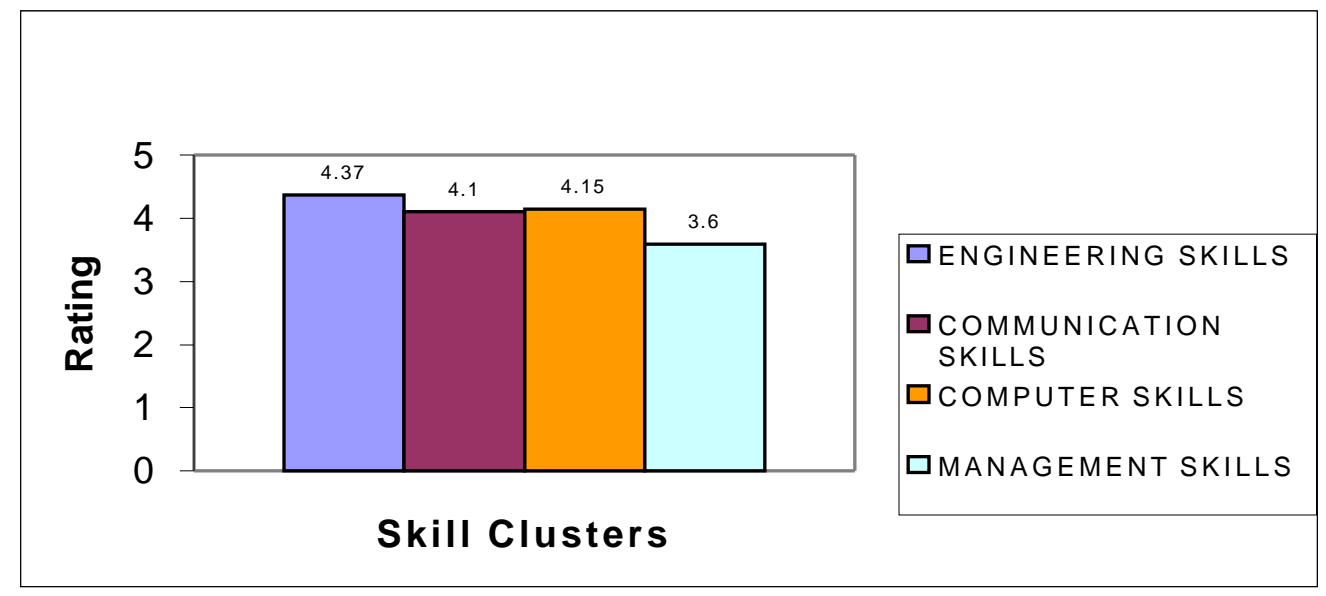

Figure 8: Civil Engineering program Senior Capstone Project Students’ Rating

"Proceedings of the 2002 American Society for Engineering Education Annual Conference \& Exposition Copyright (C) 2002, American Society for Engineering Education" 
Senior Year Students Skill Rating:

The rating given by the senior year students in the civil engineering program are shown in

Figure 8. During the senior year, the ranking is as follows

1. Engineering skills,

2. Computer skills,

3. Communication skills, and

4. Management skills.

Engineering skills are to be given importance, as they are our main missions. The computer skills get higher ratings at this stage, because students would have used at least one software package for the senior capstone project. The communication skills are given lower ranking than computer skills as they fall under the interpersonal phase. During the senior capstone project, the students would have interacted with their sponsors and would have had to make presentations, and write reports. This experience would have made them feel that they are not sufficiently skilled in this area. This might be anticipated given that the university can only approximate realworld experiences. It is then up to each student to shape his skills to the specific situations provided by real-world employment. A major goal of the revised curriculum is to help students understand that their academic experiences may differ from those encountered in an actual industrial situation, and that they need to be sufficiently flexile to modify their behaviors accordingly.

By the senior year, the management skills are given the lowest ranking. This signifies two things - that students want the institution to give more importance to management skills and the second - that they feel they are not skilled enough in this area. The reason for the second is that the students have gained a glimpse of real-world experience through the senior capstone project.

Since the senior year concentrates heavily on leadership skills, students are bound to give them more importance and also feel that they are not skilled enough. Even though they have been exposed to the real-world projects through out the curriculum, it is only during the senior capstone project, that they are required to communicate extensively with the external project sponsor and plan the phases of the project in accordance with the instructions of the sponsor.

Future plan

Based on the above interpretation, we propose to give emphasis to those skill clusters that suit the phase level the student is in. Even though most of the skills are addressed during all the four years, priority for the skills to be tracked will be matched with the student's stage of development. Our new strategy will be to develop, apply and test a model for an innovative undergraduate curriculum assessment. It will be achieved by:

(1) Monitoring and continuously improving the curriculum through individually and progressively assessing the skills of the students in key courses throughout all four years of the curriculum.

(2) Establishing benchmarks that will indicate progress towards attaining acceptable performance in all these skill areas.

(3) Creating a tracking mechanism for continuous assessment of student skill and a feedback mechanism for improving the skills of students who lag behind.

"Proceedings of the 2002 American Society for Engineering Education Annual Conference \& Exposition Copyright (C) 2002, American Society for Engineering Education" 
(4) Developing a comprehensive template that contains a matrix of expectations and objectives in connection with each level of the engineering curriculum.

(5) Creating a partnership of alumni, industry representatives, and faculty in the establishment of a design assessment panel to become involved in the curriculum and assessment.

If the new curricular reform plan is implemented, the students will learn the skills in accordance with to their learning phase. This will lead to a better understanding and mastery of those skills. The faculty will know the stage the student is currently in, due to the continuous tracking of skills of individual students. This will help the faculty to guide each student effectively through the courses and will enable each student to get the most out of his coursework.

\section{Acknowledgment}

We would like to thank NSF for their grant no. 9872433, "Integrating Engineering Design with Humanities, Social Sciences, Sciences and Mathematics", which helped us in implementing our curricular reforms. We would like to thank the Co-PIs of the grant, Professors Donald Leone, Leo Smith, Hisham Alnajjar, Saleh Keshawarz, and Ladimer Nagurney for their co-operation and efforts. We would like to thank Dean Alan Hadad for his support. The authors also thank Suresh K Ramasamy, Graduate Student, for his contribution in the preparation of this paper.

\section{Bibliography}

1. Denton, Denice D. "Engineering Education for the $21^{\text {st }}$ century: Challenges and opportunities", Journal of Engineering Education, January 1998, pp.19-22.

2. Everett, L., Imberie, P., Morgan. J., "Integrated Curricula: Purpose and Design”, Journal of Engineering Education, April 2000, pp. 167-175.

3. Pendergrass, N.A. and et al, " Improving first year engineering education", $29^{\text {th }}$ ASEE/IEEE Frontiers in Education committee, Nov 1999.

4. Smith, L., and Shetty, D., "Principles of Engineering and Design: a Multidisciplinary First Year Course", ASEE Zone I Meeting - Spring 1997 Middle Atlantic Section, New England Section, St. Lawrence Section, West Point, New York 1997.

5. Shetty, Devdas and et al, "Integrating Engineering Design with Humanities, Sciences and Social Sciences Using Integrative Learning Blocks", presented at the ASEE 2001 Annual Conference, Albuquerque, June 2001.

\section{DEVDAS SHETTY}

Vernon D. Roosa Professor of Manufacturing Engineering and Associate Dean of the College of Engineering, University of Hartford. He also serves as the Director of the Engineering Applications Center. He is the principal Investigator of NSF grant on curricular reform.

\section{SUSAN COLEMAN}

Associate Professor of Finance, Barney School of Business, University of Hartford. She is the consulting faculty for the assessment part of the NSF grant on curricular reform.

"Proceedings of the 2002 American Society for Engineering Education Annual Conference \& Exposition Copyright (C) 2002, American Society for Engineering Education" 